
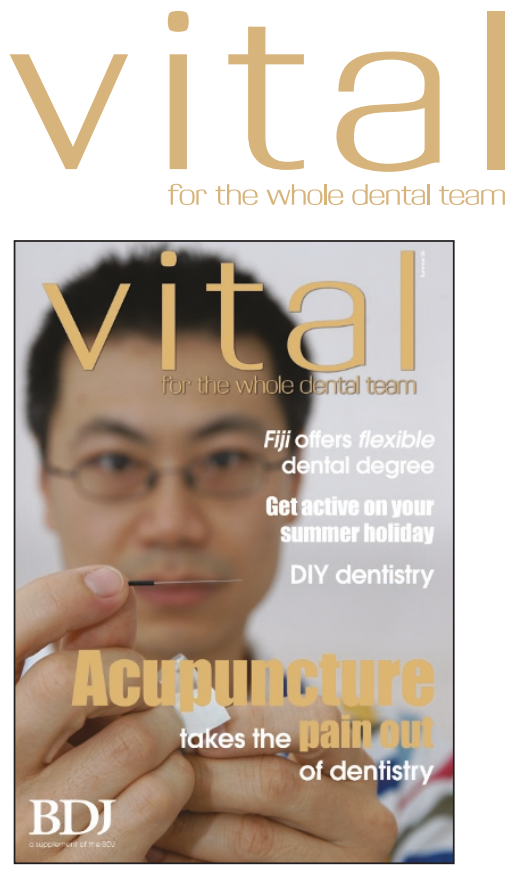

VITAL for the whole dental team

Editor-in-Chief: Stephen Hancocks OBE

Editor: Haroon Ashraf

Art Editor: Melissa McClean

Production Editor: Sandra Murrell

Assistant Production Editor: Esther Mckeown

Staff writers: Arveen Bajaj, Kate Maynard

Publishing Manager: Kim Black-Totham

Advertising Sales Director: Joe Aspis

Display Advertising Sales: Alison Tant

Classified Sales: Adam Pepper

Advertising enquiries: +44 (0)20 78434729

Production Controller: Sarah Smith

Vital Editorial Board: Julia Brewin, Michelle Brindley, Larry Browne, Claire Crocker, Ruth Glover, Gordon Watkins, Margaret Wilson

British Dental Journal

The Macmillan Building

4-6 Crinan Street

London $\mathrm{N} 19 \mathrm{XW}$

Tel: + $44(0) 2078433678$

Fax: + $44(0) 2078434725$

C) British Dental Journal 2005. All rights reserved. No part of this publication may be reproduced, stored in a retrieval system or transmitted in any form or by any means, electronic, mechanical, photocopying, recording or otherwise, without the prior permission of the British Dental Journal.

The opinions expressed in this publication are those of the authors and not necessarily those of the British Dental Association or the editor. Appearance of an advertisement does not indicate BDA approval of the product or service.

\section{Supported WRICLEY \\ by Oral Healthcare in Action}

\title{
Have fun in the sun
}

Welcome to the summer issue of Vital, which is bursting at the seams with articles covering everything from the legality of tooth whitening to inspiring ideas and destinations for your summer break.

One such place is the volcanic and coral islands of Fiji, which is a beautiful location for a summer holiday but have you ever thought of practising dentistry there?

Drs Shirley and Charles Scola have done just that and tell Vital about island life and a flexible dental degree offered by the Fiji School of Medicine (see page 31).

Our cover story is about acupuncture, which may not be

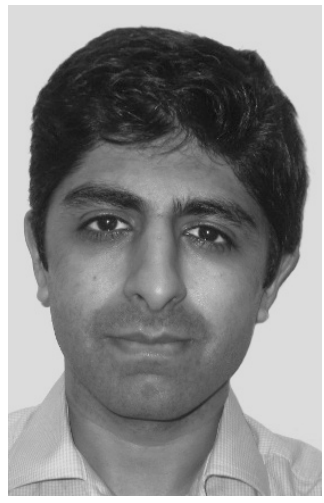
the first treatment that springs to mind when you think of services available at a dental practice.

But this ancient Chinese medicine is one of the biggest complimentary therapies in the West and is used by a growing number of dentists to treat dental-related problems such as anxiety and gag reflex.

We take a closer look with south London dentist and acupuncturist Peter Kosasih who is a powerful advocate for this relaxing and pain-relieving therapy (see page 27).

Vital is the first publication aimed at the whole dental team and it is likely that legislation for statutory registration will be discussed in Parliament later this year.

When registration becomes law, dental-team organisations, such as the British Dental Receptionists Association, will play a key role in supporting their members.

We profile the main groups and ask them for their views on registration and what benefits they offer members (see page 19).

We continue this theme in our regular perspectives feature (see page 14) where Julie Ferry asks members of the dental team what it means to be a professional.

We delve deeper into this issue and examine the professional needs of hygienists in Scotland in a study by the President of the British Dental Hygienists' Association Margaret Ross (see page 23).

And Arveen Bajaj interviews three dental access coordinators to give us an idea of what it's like to do this tough but rewarding job (see page 35).

Vital's regulars such as the diary, news, marketplace, reviews, and spotlight are all still here and in the Last Word Stephen Hancocks looks at DIY dentistry (see page 54).

Of course Vital isn't all about work and with summer upon us, Kate Maynard offers a selection of ideas for your summer break.

So if you have ever considered naturism or snorkelling or doing both at the same time, check out her tips on how to get started on these and many other fun ideas (see page 39).

We are already looking forward to putting together the next issue and we would love to include your feedback. So don't forget to drop us a line and share your views with your fellow dental professionals.

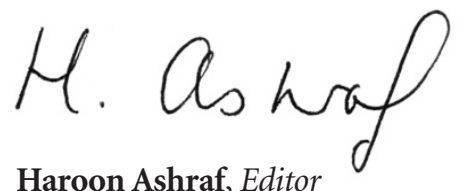

